\title{
Unresectable Adrenal Cortex Carcinoma
}

National Cancer Institute

\section{Source}

National Cancer Institute. Unresectable Adrenal Cortex Carcinoma. NCI Thesaurus. Code C150580.

Adrenal cortex carcinoma that is not amenable to surgical resection. 